\title{
Numerical Analysis of Crack Failure of Reinforced Thermoplastic Pipe (RTP)
}

\author{
Jonathan Emmanuel Edmund ${ }^{1,}{ }^{*}$ and Zahiraniza binti Mustaffa ${ }^{1}$ \\ ${ }^{1}$ Department of Civil Engineering, Universiti Teknologi PETRONAS, Seri Iskandar, 31750, Malaysia
}

\begin{abstract}
Composite pipeline can drastically reduce losses caused by corrosion that occurs in carbon steel pipes in the industry. Multiple numerical testing has been conducted to determine maximum stress and strain a Reinforced Thermoplastic Pipe (RTP) can withstand before hitting failure. Not many studies were done to find the maximum stress intensity a defected RTP can resist before failing. Objectives are to validate the numerical model for Reinforced Thermoplastic Pipeline (RTP) to industry standard and to analyze the maximum stress intensity of Reinforced Thermoplastic Pipes (RTP) can withstand with various size of defects under constant pressure and incremental internal pressure with constant crack defect. Results were, under constant internal pressure of $6 \mathrm{MPa}$, the pipe will fail with a defect length of $2.05 \mathrm{~mm}$ and at constant design pressure of $10 \mathrm{MPa}$, the pipe will fail with a defect length of $0.3 \mathrm{~mm}$. At constant crack depth and width, crack tip propagation (failure) is more dependent on internal pressure rather than crack length. However, when comparing the severity of crack depth to internal pressure, crack depth is the major cause of failure.
\end{abstract}

\section{Background of study}

The oil and gas companies are suffering major losses from carbon manufactured type of pipelines due corrosion that occurs internally and externally. Airborne, a company, which is based in the Netherlands, says that an estimated $50 \%$ of leakage issues are caused by corrosion [1].

The main cause of corrosion is because of the presence of sea water and the fluid or gas that is transported using the inner liner of the pipe. Studies that were done shows that the cost of corrosion is estimated to be USD0.40 for each barrel produced and an estimate amount of USD1.4billion is annually attributed to corrosion in the US oil and gas industry [2].

Another study done by [3] states that $50 \%$ of all pipeline cost are always related to corrosion. An example of a composite pipe is shown in Figure 1 is a basic structure form of a Reinforced Thermoplastic Pipe (RTP).

\footnotetext{
* Corresponding author: jonathan_g03672@utp.edu.my
} 


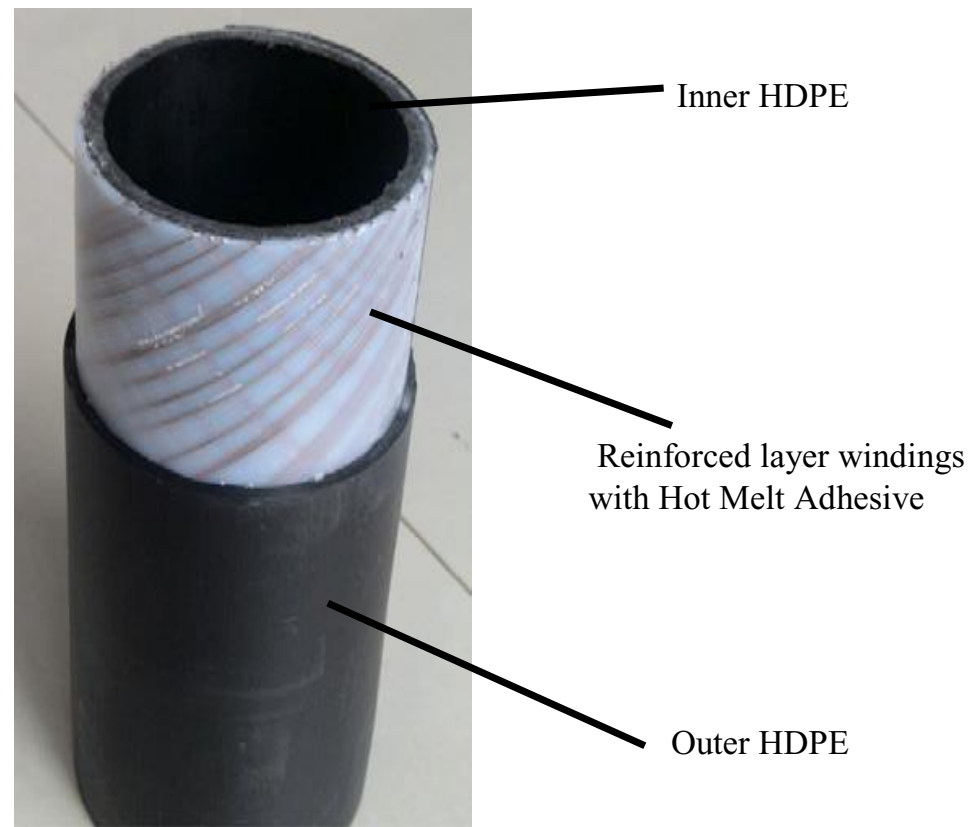

Fig.1. Structure Of RTP (Picture extracted from [4])

The RTP consists of three layers which are the inner thermoplastic liner, two structural reinforced layers made of thermoplastic polyethylene (fibre-reinforced PE) or armoured wired and an outer thermoplastic cover. The inner liner and outer cover are designed to carry the product and provide protection to the reinforced layers from the external corrosion damage [5].

The initial cost of RTP is $30 \%$ lower than carbon steel pipeline. Overall, it is $27 \%$ cheaper to construct, repair if needed and maintained [6]. Thus, making Reinforced Thermoplastic Pipe in the oil and gas industry a better option than carbon steel pipes.

\subsection{Problem statement}

Defects that happen in between different types of materials in general are hard to detect because it consists of layers which differs in density composition. A crack can greatly affect the stress and strain that the pipeline is able to withstand across the layers before it hits failure. Multiple modeling and test have been conducted to determine maximum stress and strain a RTP pipe can withstand before hitting failure $[4,7,8]$. However, not many calculation and in depth numerical modeling has been done to determine the maximum stress if a defect/crack is already present across a layer of the pipe.

The objectives of this research are to numerically develop Reinforced Thermoplastic Pipeline (RTP) (controlled pipe/unit) and to analyze the maximum equivalent stress of Reinforced Thermoplastic Pipes (RTP) can withstand with various size of defects and internal pressure.

\subsection{Composite pipe configuration}

Composite pipes can be broken down into two categories which are bonded (one material) or unbonded composite pipeline. Both has its own advantages and limitations. Bonded composite pipeline or better known as Thermoplastic Composite Pipeline (TCP) was 
developed by Airborne Oil and Gas. The bonded or unbonded (Reinforced Thermoplastic Pipe) has always been designed to adapt to the condition that it is exposed to.

Figure 2 shows the windings of carbon fiber wires around the thermoplastic pipe. The configuration consists of three basic layers which include a thermoplastic liner, a continuous helically wrapped high strength fiber reinforcement and an external thermoplastic sheath. The main purpose of the inner liner (HDPE) is to prevent the inner wall from collapsing and works as a bladder to the fluids running internally. The reinforcement layer on the other hand increases the maximum strength structurally and the twisting motion of the wire provides high tensile strength. The outer sheath protects the load bearing fiber reinforcement and provides extra strength from external pressure [9]. The inner and outer layer specialty is to prevent corrosion from happening compared to a conventional pipe.

The holt-melt adhesive is made from Polyethylene (PE) matrix. The hot-melt adhesive is used to stick the inner lining and the outer jacket to the reinforced layer and it fully integrates with the HDPE when it is heated together. The reinforced layer fully integrates with the HDPE layers because the hot-melt adhesive is made from the similar material. Thus, forming a very strong composite pipeline $[1,6]$.

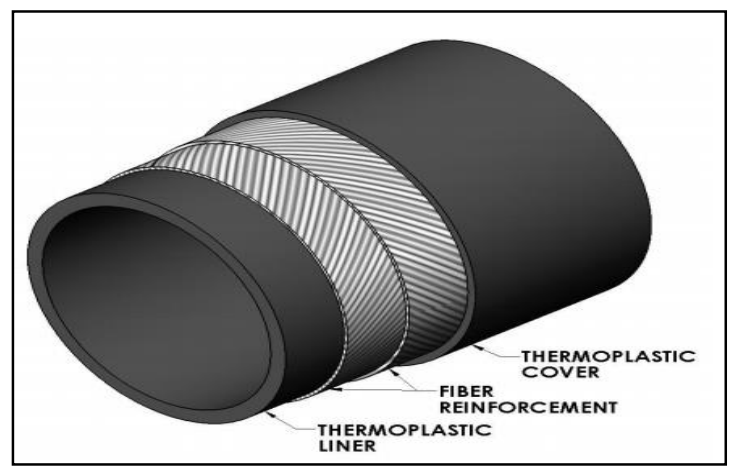

Fig.2. Configuration of Reinforced Thermoplastic Pipeline (RTP)

\subsection{Material Selection}

The three-layer RTP is for more conventional usage such as oil and gas field and subsea structure if it does not exert extreme external pressure $[1,11]$ and is far more recognizable and easier to maintain. The basic internal and external sheath can be made from different types of thermoplastic. However, high pipe grade Polyethylene (PE) has been widely used for offshore applications as is best suited of oil and gas [1]. It is widely used because of the unique elastic-plastic characteristic of it $[4,7]$.

\subsection{High density polyethylene (HDPE)}

The selection of the outer and inner sheath is crucial to this paper. Comparing three type of HDPE such as HDPE 63, HDPE 80 and HDPE 100 will give a better understanding towards the characteristics and properties of the different type of HDPE. Therefore, other properties such as thermal resistance and mechanical properties of thermoplastic material under heating, evaluation of thermal oxidation resistance applied on RTP by Oxidation Induction Time (OIT) test and the chemical bonding structures of HDPE that affects HDPE over time will not be included when selecting the HDPE grade/type [4]. 
Table 1. Minimum Required Strength (MRS), for the particular material classification (PE 100, PE 80, PE 63), gives the maximum allowable hydrostatic design stress(Table from[12]).

\begin{tabular}{|c|c|c|}
\hline $\begin{array}{c}\text { Designation of } \\
\text { material }\end{array}$ & $\begin{array}{c}\text { MRS at } \mathbf{5 0} \text { years and } \\
\mathbf{2 0 ^ { \circ } \mathbf { C }} \mathbf{~ M p a}\end{array}$ & $\begin{array}{c}\text { Maximum allowable } \\
\text { hydrostatic desig } \\
\text { stress, } \mathbf{\sigma}-\mathbf{M p a}\end{array}$ \\
\hline PE 100 & 10 & 8 \\
\hline PE 80 & 8 & 6.3 \\
\hline PE 63 & 6.3 & 5 \\
\hline
\end{tabular}

A standard way of portraying the primary mechanical property of HDPE and tensile strength is via graph of log stress vs. log time to failure. Stress regression line is formed. It is a plot of the hoop stress (circumferential) in the wall of the pipe (ID) against time of failure. The method of calculation is an internationally accepted procedure described in ISO/TR 9080. The required values of stress and time are specified in SABS ISO 4427 [12].The stress-strain relationship for HDPE is non-linear as it depends on the strain and strain-rate. Table 2 shows the physical and mechanical properties of PE 100 that is being used in this research paper.

Table 2. Physical and Mechanical of PE100 (Table extracted from [8])

\begin{tabular}{|c|c|c|c|c|}
\hline Property & Symbol & Standard & Unit & Value \\
\hline $\begin{array}{l}\text { Density } \\
\text { (compound) }\end{array}$ & $\rho_{\mathrm{m}}$ & ISO/R 1183 & $\mathrm{~g} / \mathrm{cm}^{3}$ & $0.9600-0.9609$ \\
\hline $\begin{array}{l}\text { Yield stress } \\
(100 \mathrm{~mm} / \mathrm{min})\end{array}$ & $\sigma_{\mathrm{y}}$ & $\begin{array}{l}\text { ISO/DIS } \\
6259,2\end{array}$ & $\mathrm{MPa}$ & $>25$ \\
\hline $\begin{array}{l}\text { Young's- } \\
\text { modulus }\end{array}$ & $E_{\mathrm{m}}$ & ISO $527-2$ & $\mathrm{MPa}$ & 1205 \\
\hline Poisson's ratio & $\nu_{\mathrm{m}}$ & & & 0.4 \\
\hline $\begin{array}{l}\text { Elongation } \\
\text { at break } \\
(100 \mathrm{~mm} / \mathrm{min})\end{array}$ & $\varepsilon_{\max }$ & $\begin{array}{l}\text { ISO/DIS } \\
6259,2\end{array}$ & $\%$ & $>600$ \\
\hline
\end{tabular}

\subsection{Reinforced Layer}

One of the main reason the reinforced layer is present is to avoid abrasion between outer layer and the inner layer and to provide extra axial strain properties. The reinforced layer can be made from carbon fiber, fiber-glass, aramid fiber, plastic of the same material or metallic compound such as steel strips, armored wire or cords. Each of it has its own advantages and disadvantages given different environmental situation.

Carbon fiber reinforced layer exhibits characteristic such as low weight, high strength and high stiffness in the reinforced pipeline. Glass fiber on the other hand has low or limited chemical resistance and must normally be protected by a thin layer of resin that is applied during the construction of the RTP. Generally, glass fiber it is inexpensive and has good mechanical properties. Aramid or para-aramid have low weight, high strength and moderate stiffness. Reinforced structure Steel strips on the other hand is used for lighter type of loads such as water irrigation and power cables [13].

Like carbon fiber, aramid fibers are high-performance fibers. Aramid is a synthetic organic polymer produced by a spinning process. After that, the fibers are heated and stretched to achieve high strength [13]. However the stiffness of the aramid fibers are lower 
compared to carbon fiber or fibre-reinforced PE due to the fact that aramid fibers will stretch when flexural stress in applied to it [6].

Even though reinforced layer has only good axial mechanical properties such axial strain and does not provide much flexural stress [9]. The presence of aramid fibres as an reinforced layers prevents the HDPE from undergoing sudden crack and bursting because of it being a very brittle material [14].

\subsection{Mechanics of stress and strain in rtp (intact - controlled)}

The calculation to obtain the design strength of the Reinforced Thermoplastic can be obtained from equation (1) - (9). To take the material linearity in the ANSYS FE model, the material of the RTP is modeled with linear parameters (isotropic properties). The material made from HDPE which is the cover and the liner is modeled as follows:

$$
\sigma=\frac{E_{0}}{k}[1-\exp (-k \varepsilon)]
$$

where the $\sigma$ and $\varepsilon$ are the stress and strain respectively. The dimensionless $k$ can be determined by experiments. $E_{P E}$, Elastic modulus of $\mathrm{PE}$ at a certain strain level is calculated as follows and $E_{o}$ is the initial elastic modulus of polyethylene (PE) [15]:

$$
E_{P E}=E_{0}\left[\frac{1}{k \varepsilon}[1-\exp (-k \varepsilon)]\right]
$$

The reinforcement layers are made from fiber-reinforced PE composite. It is model based on material mechanical behavior. The elastic modulus of matrix material is given as $E_{m}$. It is done by using micromechanics equations. The elastic modulus of the material is calculated using the concept of 'equivalent strain' [15]:

$$
E_{m}=E_{0}\left[\frac{1}{k \bar{\varepsilon}}[1-\exp (-k \bar{\varepsilon})]\right]
$$

The equivalent strain, $\bar{\varepsilon}$ is calculated as stated [15]:

$$
\bar{\varepsilon}=\sqrt{\frac{2}{3}\left[\left(\varepsilon_{1}^{m}-\varepsilon_{2}^{m}\right)^{2}+\varepsilon_{2}^{m^{2}}+\varepsilon_{1}^{m^{2}}\right.}
$$

The $\varepsilon_{1}^{m}$ and $\varepsilon_{2}^{m}$ are strains of the reinforced fiber matrix material in transverse directions. The transverse moduli of the reinforced layers in the Reinforced Thermoplastic Pipe could be equal to the next values of the PE matrix material $[5,10,15]$. The elastic parameters of the fiber-reinforced PE layer are revised using the formula below:

$$
\begin{gathered}
E_{1}=E_{f} V_{f}+E_{m} V_{m} \\
E_{2}=\frac{E_{m}}{V_{m}\left(1-v_{m}^{2}\right)} \\
V_{12}=v_{f} V_{f}+v_{m} V_{m} \\
V_{12}=v_{f} V_{f}+v_{m} V_{m} \\
G_{21}=\frac{G_{m}}{V_{m}}
\end{gathered}
$$


$E_{f}$ is the elastic modulus of the reinfored fibers. $v_{m}$ and $v_{f}$ is the Poisson's ratio of matrix material and fibers, respectively. $V_{m}$ and $V_{f}$ is the volume fraction of matrix material and the volume fraction of fibers, $G_{m}$ is calculated as $\left(E_{m} / 2\left(1+v_{m}\right)\right)$.

\subsection{Fracture mechanics in ANSYS mechanical 15.0}

Fracture mechanics makes it possible to determine whether a crack of a given length in a material with a known fracture toughness will propagate to a fracture (failure) at a given stress level [16]. The key thing in fracture mechanics is to find out whether the crack will propagate into a severe fracture (failure). Fracture mechanics uses the stress intensity factor $(\mathrm{K})$ and compare it to the material fracture toughness $\left(\mathrm{K}_{\mathrm{IC}}\right)$ [17], if the stress intensity $(\mathrm{K})$ is above the material fracture toughness $\left(\mathrm{K}_{\mathrm{IC}}\right)$, it will propagate and fail.

\subsubsection{Stress intensity factor (K, SIF, Modes)}

From the derivation of theory of elasticity (isotropic materials), stress distribution happens at the tip of the crack. Fracture mechanics is built upon this theory. As stress levels approach infinity at the tip of the crack (because $r$ is near to 0 ), the equivalent stress obtained is not accurate and thus stress intensity is used to obtain the best results. $r$ is the distance from the tip of the crack till the nearest calculation point.The fracture behavior can be known from the derivation of the value of $\mathrm{K}$. After obtaining the value of $\mathrm{K}$. K1, K2 and $\mathrm{K} 3$ (Mode 1,2 and 3) can be calculated[16] .

The formulas to derive the stress intensity factor $(K)$ is given from equation $(10),(11)$ and (12) from the applied loading. From the formula it is known that the stresses are near infinite at the crack tip, however by using the derived expression we can obtain the K.

$$
\begin{gathered}
\sigma_{X X}=\frac{K_{1}}{\sqrt{2 \pi r}} \cos \frac{\theta}{2}\left\lfloor 1-\sin \frac{\theta}{2} \sin \frac{3 \theta}{2}\right\rfloor \\
\sigma_{Y Y}=\frac{K_{1}}{\sqrt{2 \pi r}} \cos \frac{\theta}{2}\left\lfloor 1+\sin \frac{\theta}{2} \sin \frac{3 \theta}{2}\right\rfloor \\
\sigma_{X Y}=\frac{K_{1}}{\sqrt{2 \pi r}} \cos \frac{\theta}{2} \sin \frac{\theta}{2} \sin \frac{3 \theta}{2}
\end{gathered}
$$

In fracture mechanics, three different modes from which the stress intensity factor of a crack can be calculated. As shown in Figure 3, Mode 1 is K1, Mode 2 is K2, Mode 3 is K3. Mode 1 is tensile or opening mode. Mode 2 is sliding, or shear mode and Mode 3 is tearing mode. Typically, $\mathrm{K} 1$ is the most severe [16] among all three modes and therefore, it will be used in this research. 


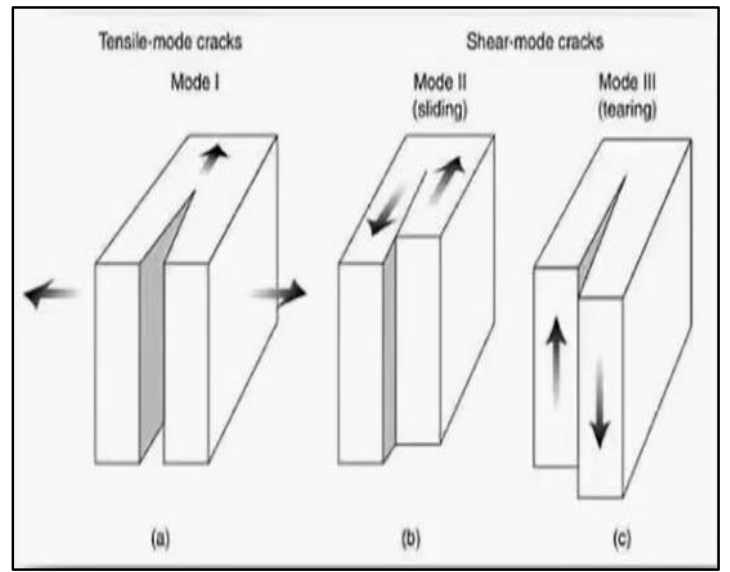

Fig.3. Different Modes of stress intensity factor K1, K2 and K3. (Figure obtained from [17])

In linear elastic materials and in plane stress, the energy release rate $(G)$, the $J$ integral and the stress intensity factor (K or SIF) are related. Therefore, there is more than one way to obtain the $\mathrm{K}$ value. The relation is show in equation (13):

$$
J=G=\frac{K^{2}}{E}
$$

\subsubsection{Fracture toughness}

Fracture toughness $\left(K_{I C}\right)$ is a measured and known material property. As stated if $\mathrm{K}>K_{I C}$, the crack will become critical and immediately propagate till failure. If the stress intensity factor $(\mathrm{K})$ is less than fracture toughness of the material $\left(K_{I C}\right)$ the crack will still propagate. However, the crack is known as still "safe" because it is a slow crack growth (SCG) or controlled growth [17] and still may fail over a longer period of time. Below is the formula used to determine and compare the stress intensity to fracture toughness (14):

$$
K=Y \sigma \sqrt{2 \pi a}
$$

Where, $\mathrm{K}=$ Stress intensity factor

$\mathrm{Y}=$ Geometry Proportion

$\sigma=$ Stress

$\mathrm{a}=$ Crack Size

Fracture toughness $\left(K_{I C}\right)$ is based on material properties and therefore is a known value[16]. Therefore, comparison of the K obtained from ANSYS Mechanical 15.0 through its finite element calculations and $K_{I C}$ can be done.

Only the High-Density Polyethylene (HDPE) section of the pipe will be studied, since ANSYS Mechanical 15.0 has limitation that cracks can only be on a single geometry and not multiple geometries. In addition, the crack is either located in the outer or inner layer of the Reinforced Thermoplastic Pipe (RTP) based on the severity of it.

A research done by [18] states the HDPE 100 has a fracture toughness of $0.73 \mathrm{MPa} \mathrm{m} \mathrm{m}^{0.5}$ or 23.08 $\mathrm{MPa} \mathrm{mm} \mathrm{m}^{0.5}$, another study done by [19] shows that the fracture toughness of uniquely built Polyethylene ranges from $0.8 \mathrm{MPa} \mathrm{m}^{0.5}$ to $1.7 \mathrm{MPa} \mathrm{m}^{0.5}$ or $25 \mathrm{MPa} \mathrm{mm} \mathrm{m}^{0.5}$ to $60 \mathrm{MPa} \mathrm{mm} \mathrm{m}^{0.5}$. Dielectric Cooperation a company based in Germany states that their normal $\mathrm{PE} 100$ fracture toughness under normal environmental temperature is $0.6 \mathrm{MPa} \mathrm{m}^{0.5}$ to $0.75 \mathrm{MPa} \mathrm{m}^{0.5}$ or $18 \mathrm{MPa} \mathrm{mm} \mathrm{m}^{0.5}$ to $23 \mathrm{MPa} \mathrm{mm} \mathrm{m}^{0.5}$. 
As a conclusion of fracture toughness, a slight change in temperatures or the amount of lining of which the HDPE is constructed [19] prior to the testing can greatly affect the results of fracture toughness obtain. Therefore, for this research, the fracture toughness of $0.73 \mathrm{MPa} \mathrm{m} \mathrm{m}^{0.5}$ or $23.08 \mathrm{MPa} \mathrm{mm} \mathrm{m}^{0.5}$ was chosen because this particular HDPE 100 [18] shows the most similarities in terms of physical and mechanical properties to this research and Soluforce pipes.

\section{Simulation setup}

The research involves a numerical model for stress and strain analysis using ANSYS Mechanical Finite Element Modeling.

\subsection{Reinforced thermoplastic pipe dimensions \& crack sizing}

This research is using $150 \mathrm{~mm}$ in outer diameter pipe for this research because it can handle larger amount of stress and strain when force is applied. The length of the pipe chosen was $1000 \mathrm{~mm}$. The thickness of the pipe is $12.5 \mathrm{~mm}$ as stated in the Soluforce pipes manufacturer for subsea pipes up to 100 to 150 meters in depth. The outer HDPE 100 and Inner HDPE 100 are both $6 \mathrm{~mm}$ respectively. The reinforced aramid fiber is $0.5 \mathrm{~mm}$. By adding up and bonding all the 3 layers together, we would obtain $12.5 \mathrm{~mm}$ in thickness.

The type of crack and the generation of the crack angle has its limitation in ANSYS Mechanical 15.0. The type of crack that is induced is semi-elliptical and the highest stress intensity generated is at the tip of the semi-elliptical. The angle selected is perpendicular to the pipe angle. The crack angle is located at $270^{\circ}$ from clockwise and perpendicular to the pipe. The dimension of the crack being induced is $0.3 \mathrm{~mm}$ length (5\% of thickness), $0.05 \mathrm{~mm}$ height and $0.1 \mathrm{~mm}$ width. The selection of $5 \%$ defect thickness is the basic practice standard of crack in relation to the height and width of the crack of API standard.

\subsection{RTP Properties used and mesh settings in ANSYS 15.0.}

HDPE 100 should be able to have a minimum characteristic tensile strength and strain. The isotropic properties used for HDPE and aramid fibre are shown in Table 3 and 4.

Table 3. Mechanical and Isotropic Properties of HDPE 100

\begin{tabular}{|c|c|}
\hline \multicolumn{2}{|c|}{ Mechanical Properties } \\
\hline Density & 0.975 \\
\hline Isotropic Elasticity & \\
\hline Young's Modulus & $\mathrm{MPa}$ \\
\hline Poisson Ratio & 0.42 \\
\hline Bulks Modulus & $\begin{array}{c}2916.7 \\
\mathrm{MPa}\end{array}$ \\
\hline Shear Modulus & $\begin{array}{c}492.9 \\
\mathrm{MPa}\end{array}$ \\
\hline Tensile Yield Strength & $36 \mathrm{MPa}$ \\
\hline $\begin{array}{c}\text { Tensile Ultimate } \\
\text { Stength }\end{array}$ & $40 \mathrm{MPa}$ \\
\hline
\end{tabular}


Table 4. Mechanical and Isotropic Properties of Aramid Fibre

\begin{tabular}{|c|c|}
\hline \multicolumn{2}{|c|}{ Mechanical Properties } \\
\hline Density & $1.37 \quad$ to \\
\hline Isotropic Elasticity & \\
\hline Young's Modulus & $\mathrm{MPa}$ \\
\hline Poisson Ratio & 0.36 \\
\hline Bulks Modulus & $\begin{array}{c}83330 \\
\mathrm{MPa}\end{array}$ \\
\hline Shear Modulus & 25740 \\
$\mathrm{MPa}$ \\
\hline Tensile Yield Strength & $\mathrm{MPa} 360$ \\
\hline $\begin{array}{c}\text { Tensile Ultimate } \\
\text { Stength }\end{array}$ & $\mathrm{MPa}$ \\
\hline
\end{tabular}

The thickness of aramid fibres is $0.5 \mathrm{~mm}$. The mechanical properties of the aramid fibres are as shown in Table 4. As seen, the mechanical and isotropic properties of the aramid fibre is much stronger than of the HDPE 100. Therefore, the focus of the entire stress and strain will be focused on the Inner and Outer HDPE layers.

The quality of the mesh greatly effects the number of elements present in the body. The finer or more detail the mesh, the quality of the finite element calculation becomes much more accurate. The mesh settings are constant throughout the entirety of this research as shown in Table 5.

Table 5. Mesh Settings in ANSYS Mechanical version 15.0

\begin{tabular}{|l|l|}
\hline \multicolumn{2}{|l|}{ Meshing Settings } \\
\hline Curvature Function & On \\
\hline Curvature Angle & $18^{\circ}$ \\
\hline Min size & $9 \mathrm{~mm}$ \\
\hline Max face size & $10 \mathrm{~mm}$ \\
\hline Max size & $11 \mathrm{~mm}$ \\
\hline Growth Rate & 2.0 \\
\hline Nodes & 454352 \\
\hline Elements & 208475 \\
\hline
\end{tabular}

\section{Results}

\subsection{Intact reinforced thermoplastic pipe (RTP) validation}

Soluforce pipes states that the maximum stress allowable before hitting failure is $10 \mathrm{MPa}$ of pressure at water depths ranging from 50 to 150 meters. The constant external pressure applied onto to pipe is $1 \mathrm{MPa}$ to $2 \mathrm{MPa}$.

Due to certain limitations of the ANSYS Mechanical Education, a maximum of $9 \mathrm{MPa}$ internal pressure could be simulated before the HDPE 100 layers reaches its ultimate yield stress and the for the 9.5 MPa and $10 \mathrm{MPa}$ would be extrapolated as shown in Figure 6. 
Figure 4 shows the equivalent stress through all the three layers of the RTP. The stress is evenly distributed throughout the entire three layers of the pipe, thus making it a good simulation without compromising the quality of the mesh.

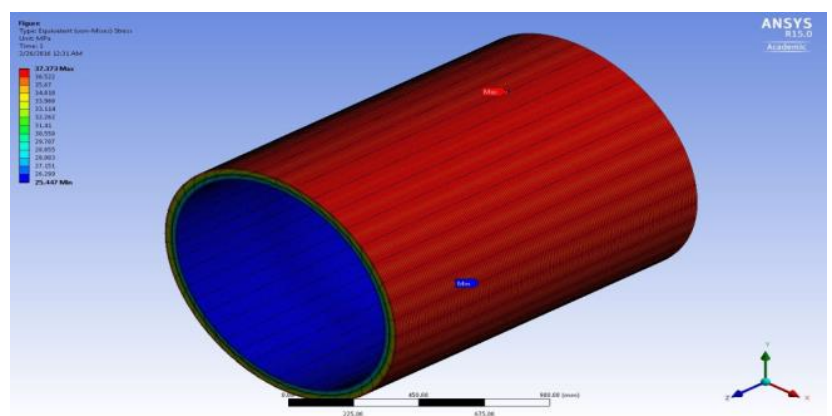

Fig.4. Equivalent Stress in the RTP when $9 \mathrm{MPa}$ is applied internally and a constant external pressure of $2.5 \mathrm{MPa}$.

With an internal pressure of $9 \mathrm{MPa}$ and external hydrostatic pressure of $2.5 \mathrm{MPa}$ the equivalent stress was $37.373 \mathrm{MPa}$ as shown in Figure 5, the highest stress is located at 2 to $3 \mathrm{~mm}$ from the outer most layer of the HDPE 100 wall.

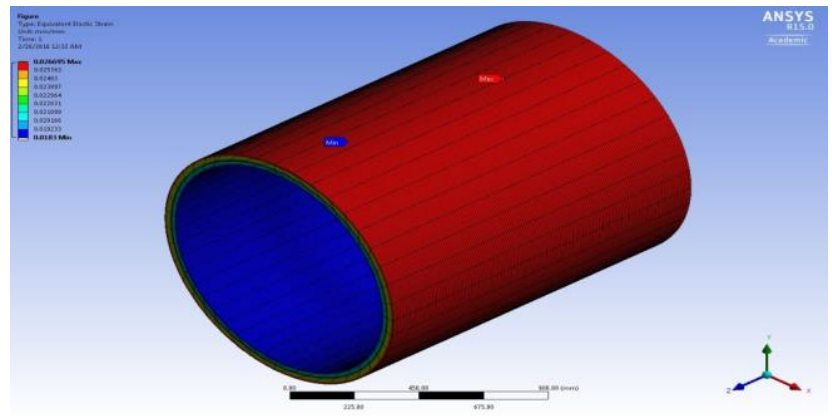

Fig.5. Equivalent Strain in the RTP when $9 \mathrm{MPa}$ is applied internally and a constant external pressure of $2.5 \mathrm{MPa}$.

With an internal pressure of $9 \mathrm{MPa}$ and external hydrostatic pressure of $2.5 \mathrm{MPa}$ the equivalent strain is $0.0267 \mathrm{~mm}$ as shown in Figure 5, the highest strain is located at the outer most layer of the HDPE 100 wall and does not exceed the maximum strain allowance of $7.7 \%$ [5].

Internal pressure had a constant increment of $0.5 \mathrm{MPa}$ till $9 \mathrm{MPa}$. Due to limitation of the Educational software for ANSYS, internal pressure of $9.5 \mathrm{MPa}$ and10 $\mathrm{MPa}$ were extrapolated as shown in Figure 6.

The maximum pressure stated by the manufacturer (Soluforce) is $10 \mathrm{MPa}$ or 100 bars. The equivalent stress obtained at that pressure is $39.51 \mathrm{MPa}$. Therefore, it can be concluded that the equivalent stress does not exceed the ultimate yield stress of $40 \mathrm{MPa}$ as stated by the material properties (does not fail). However, it does undergo permanent damage (permanent deformation) after the equivalent stress exceed $36 \mathrm{MPa}$. The pipe being simulated do meet Soluforce RTP standards and specifications.

Therefore, the controlled pipe simulation is validated successfully. Therefore, cracks can now be induced to achieve Objective 2 in this research. 


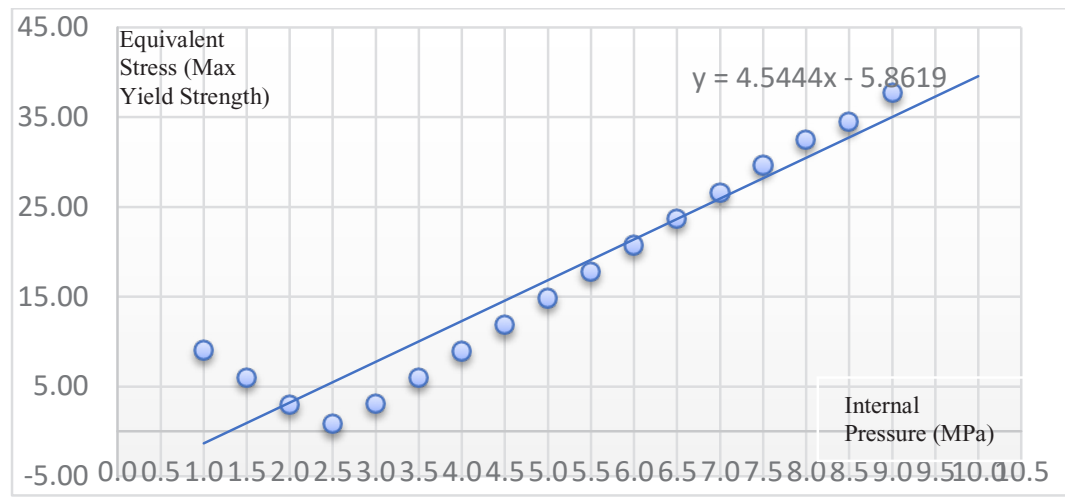

Fig.6. Equivalent stress (Max Yield Strength) when subjected to various internal pressure with a constant external pressure.

\subsection{Selection of induced crack location (Inner or Outer HDPE)}

Severity of each fracture (constant crack depth, crack width, crack height and content internal and external pressure) varies at different location of the RTP. The data obtained shows that the inner HDPE (Figure 7) has higher value in fracture analysis tool (K1) compare to the outer HDPE (Figure 8).

The stress intensity (K1) has higher value in the inner section of the pipe compared to the outer layer is due to the reason that the major principal stress/pressure exerted onto the pipe is from internal pressure [5,7] causing the internal section of the High-Density Polyethylene to show higher stress intensity at the tip of the crack.

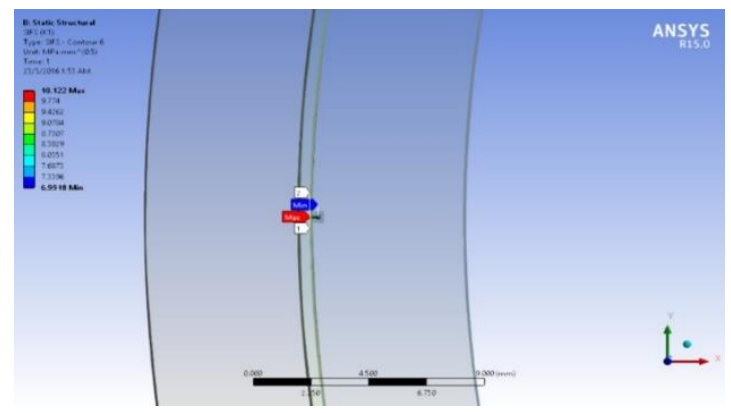

Fig.7. Stress Intensity of $10.22 \mathrm{MPa} \mathrm{mm}^{0.5}$ under a standard (hydrostatic pressure) internal pressure of $6 \mathrm{MPa}$.

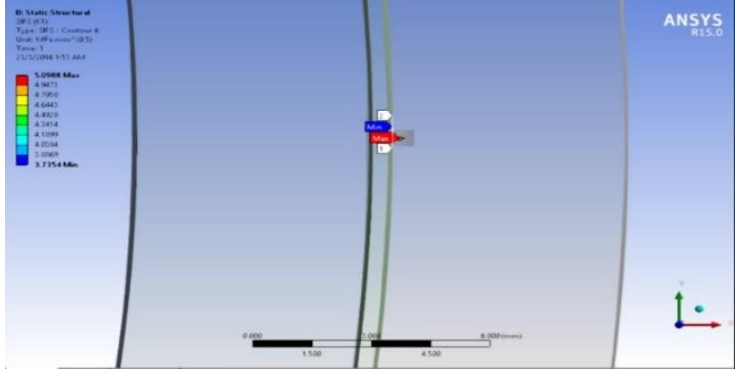

Fig.8. Stress Intensity of 5.09 MPa $\mathrm{mm}^{0.5}$ under a standard (hydrostatic pressure) internal pressure of $6 \mathrm{MPa}$. 
A reason why the outer section of the HDPE shows lower value is because that much of the stress has be dissipated/absorbed in the $0.5 \mathrm{~mm}$ layer of aramid fibers [4]. However, the study was conducted by [4] uses steel wires. This proves that the Reinforcement layer does add strength towards the RTP $[8,13]$.

\subsection{Stress Intensity (K1) under various internal pressure with constant defect}

The lowest running internal pressure is $4 \mathrm{MPa}$ for most of Soluforce oil and gas pipes. Therefore, $4 \mathrm{MPa}$ was the lowest running pressure simulated in this research. From the initial results obtain, it can clearly be seen that the material data shown in Figure 9 is almost linear. The physical properties shown is calculated in isotropic elasticity calculation.

It is because the material is undergoing isotropic elasticity [5] and does not go above the ultimate yield strength of $40 \mathrm{MPa}$, the calculation is acceptable. Only after $9 \mathrm{MPa}$ internal pressure is simulated, the equivalent stress will be above the tensile yield strength and will theoretically show some signs of deformation as shown in the studies done by [8].

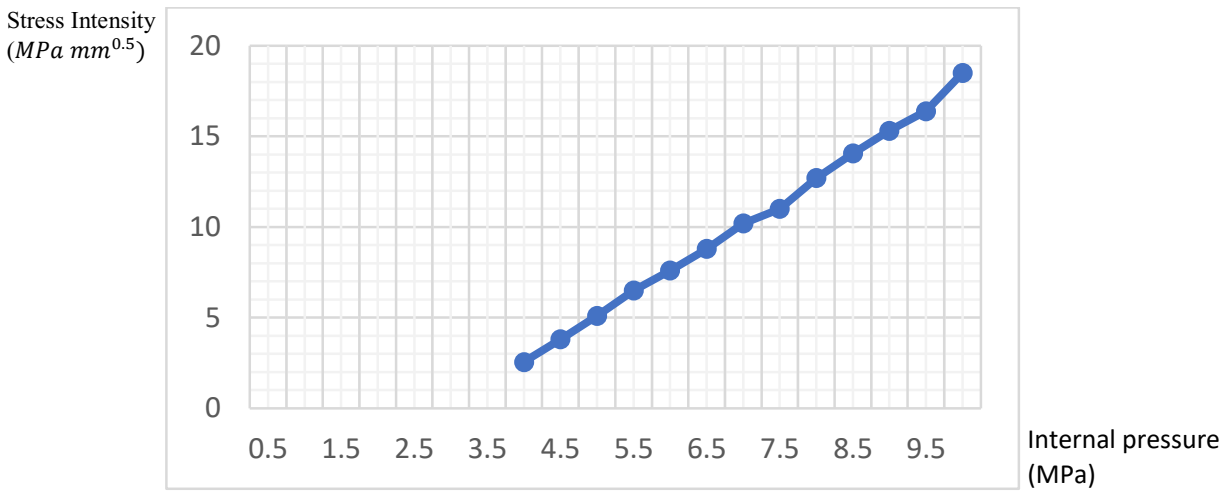

Fig.9. Stress Intensity $\left(\mathrm{MPa} \mathrm{mm} \mathrm{m}^{0.5}\right)$ vs Internal Pressure (MPa) for mode 1 simulated under various internal pressure at a constant defect length of $0.3 \mathrm{~mm}$.

From Figure 9, it can be seen that the stress intensity of the crack with a length of 0.3 $\mathrm{mm}$ does not exceed the fracture toughness of the material as stated in [18] which is 23.08 $\mathrm{MPa} \mathrm{mm} \mathrm{m}^{0.5}$ even at the maximum internal pressure being simulated at $10 \mathrm{MPa}$.

At maximum internal pressure of $10 \mathrm{MPa}$, the stress intensity factor (K1) is 18.5 $\mathrm{MPa} \mathrm{mm} \mathrm{m}^{0.5}$. This means that the pipe will not propagate till failure critically (immediately) and will fail due to fatigue, creep or slow crack growth (SCG) over time $[9,10]$. It can be said that with $5 \%$ of the defect thickness or $95 \%$ remainder thickness of the pipe will not propagate till failure critically.

\subsection{Stress Intensity (K1) under constant internal pressure of $6 \mathrm{MPa}$ with various defect (crack) length}

The smallest crack length simulated for this research was $0.3 \mathrm{~mm}(5 \%$ or internal HDPE thickness or $2.4 \%$ total thickness) with a standard running pressure of $6 \mathrm{MPa}[1,3] .36$ simulations were done with different defect length to obtain the stress intensity of the crack till it exceeds the fracture toughness of $23.08 \mathrm{MPa} \mathrm{mm}^{0.5}[18]$.

From initial data obtained, the material will be undergoing isotropic elasticity [5] and the stress intensity obtain should in theory be linear. Figure 10 shows the results obtained when simulating the crack defect of $0.3 \mathrm{~mm}$ to $0.35 \mathrm{~mm}$ defect length shows a sudden jump in the stress intensity of the crack. 
This is because the energy stored (J-integral) was already high in $0.3 \mathrm{~mm}[18,19]$, and when the defect was simulated with $0.35 \mathrm{~mm}$ defect length, the fracture zone mentioned in [17] in ANSYS mechanical will increase as well. It is mainly due to these two reasons that there is a sudden jump of stress intensity between $0.3 \mathrm{~mm}$ to $0.35 \mathrm{~mm}$ in defect length.

As seen in Figure 10, the stress intensity of the fracture only goes above the fracture toughness after $2 \mathrm{~mm}$ defect is induced. The stress intensity of the $2.05 \mathrm{~mm}$ defect is 23.10 MPa mm ${ }^{0.5}$ which is slightly above the fracture toughness of the inner HDPE which is 23.08 $\mathrm{MPa} \mathrm{mm} \mathrm{m}^{0.5}$. In Figure 10, anything above the fracture toughness (red dotted line) of the material will immediately propagate till failure.

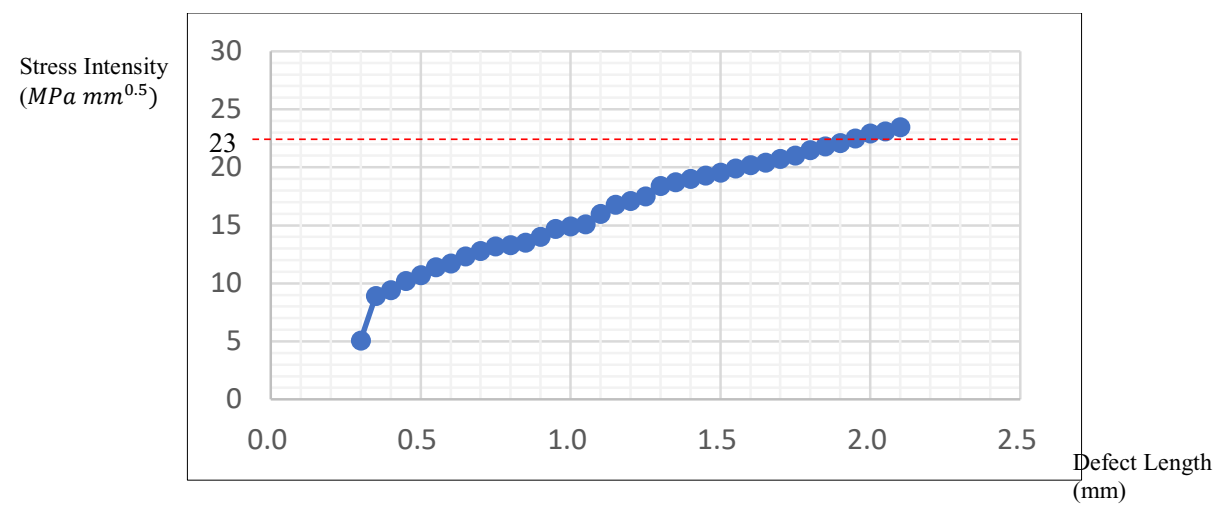

Fig.10. Stress Intensity $\left(\mathrm{MPa} \mathrm{mm}^{0.5}\right)$ vs Crack Length $(\mathrm{mm})$ for mode 1 simulated under various defect length at constant internal pressure of $6 \mathrm{MPa}$.

This means that the crack will propagate till fracture failure critically $[17,19]$ after the defect becomes larger than $2 \mathrm{~mm}$. Another way of concluding this is, at $33.3 \%$ thickness of the Inner HDPE or $16 \%$ of the total thickness of the RTP, the material will immediately propagate till failure $[17,19]$.

\section{Conclusions}

The controlled RTP was able to meet industry specifications of the ultimate yield strength being under $40 \mathrm{MPa}$. Furthermore, this research has also shown that the inner section of the HDPE suffers higher stress intensity $\left(\mathrm{MPa} \mathrm{mm} \mathrm{m}^{0.5}\right)$ compared to the outer HDPE because the primary loading is from the internal direction like the research done by [5].

Even at maximum internal pressure $(10 \mathrm{MPa})$ applied to the RTP and a $0.3 \mathrm{~mm}$ crack ( $5 \%$ thickness of inner HDPE) present, the stress intensity is $18.5 \mathrm{MPa} \mathrm{mm}^{0.5}$ which is far below the fracture toughness of the material of $23.08 \mathrm{MPa} \mathrm{mm}^{0.5}$. This shows that the pipe can still safely be used during its service life $[1,4,5$,$] . However, slow crack growth (SCG)$ will be present.

Only after $2.05 \mathrm{~mm}$ crack length is induced, that stress intensity obtained will be slightly higher than the fracture toughness of the material. The stress intensity of the $2.05 \mathrm{~m}$ $\mathrm{m}$ defect is $23.10 \mathrm{MPa} \mathrm{mm}{ }^{0.5}$ which is higher compared to the HDPE fracture toughness which is $23.08 \mathrm{MPa} \mathrm{mm} \mathrm{m}^{0.5}$ and causes the material to propagate till failure immediately.

At constant crack depth and width, crack tip propagation (failure) is more dependent on internal pressure rather than crack length. However, when comparing the severity of crack depth to internal pressure, crack depth is the major cause of failure. 
I would first like to thank my thesis advisor AP Dr Zahiraniza binti Mustaffa of the Civil and Environmental Faculty at University Teknologi PETRONAS. The door to A.Prof. Zahira office was always open whenever I ran into a trouble spot or had a question about my research or writing. She consistently allowed this paper to be my own work but steered me in the right the direction whenever he thought I needed it.

\section{References}

1. Osborne, J., Thermoplastic pipes - lighter, more flexible solutions for oil and gas extraction. Reinforced Plastics, 2013. 57(1): p. 33-38.

2. Paolo Cavassi, M.C., The Cost of Corrosion in the Oil and Gas Industry. Journal of Protective Coatings and Linings 1999.

3. Parsons, W., Pipeline Construction Drivers. Corrosion Cost and Enginerring Issues 2010.

4. Li, H., et al., Failure analysis of steel wire reinforced thermoplastics composite pipe. Engineering Failure Analysis, 2012. 20: p. 88-96.

5. Yu, K., et al., Numerical analysis of the mechanical behaviour of reinforced thermoplastic pipes under combined external pressure and bending. Composite Structures, 2015. 131: p. 453-461.

6. Luhrsen, H., Reinforced Thermoplastic Pipes. State of Development, Situation on the World Market and System Introduction in Germany, 2001.

7. Leevers, P.S., et al., High rate fracture toughness testing of thermoplastics. Polymer Testing, 2014. 33: p. 79-87.

8. Kruijer, M.P., L.L. Warnet, and R. Akkerman, Analysis of the mechanical properties of a reinforced thermoplastic pipe (RTP). Composites Part A: Applied Science and Manufacturing, 2005. 36(2): p. 291-300.

9. Bai, Q. and Y. Bai, 26 - Tensile and Compressive Strengths of RTP Pipeline, in Subsea Pipeline Design, Analysis, and Installation, Q.B. Bai, Editor. 2014, Gulf Professional Publishing: Boston. p. 599-609.

10. Bai, Q. and Y. Bai, 27 - Burst Strength of RTP Pipeline, in Subsea Pipeline Design, Analysis, and Installation, Q.B. Bai, Editor. 2014, Gulf Professional Publishing: Boston. p. 611-620.

11. Fernandez Villegas, I. and P. Vizcaino Rubio, On avoiding thermal degradation during welding of high-performance thermoplastic composites to thermoset composites. Composites Part A: Applied Science and Manufacturing, 2015. 77: p. 172-180.

12. Pipesystem, M. HDPE Physical Properties. 2010; Available from: www.marleypipesystems.co.za.

13. Bai, Q. and Y. Bai, 28 - Collapse of RTP Pipelines, in Subsea Pipeline Design, Analysis, and Installation, Q.B. Bai, Editor. 2014, Gulf Professional Publishing: Boston. p. 621-636.

14. Zheng, J., et al., Short-term burst pressure of polyethylene pipe reinforced by winding steel wires under various temperatures. Composite Structures, 2015. 121: p. 163-171.

15. Yu, K., et al., Analysis of flexural behaviour of reinforced thermoplastic pipes considering material nonlinearity. Composite Structures, 2015. 119: p. 385-393.

16. Associates, C. ANSYS Training from Expert Engineers. 2016 [cited 1 March 2016]; Available from: https://caeai.com/ansys-training.

17. Inc, C.A. Upcoming training ClassesView calendar. 2016 [cited 23 Feb 2016]; Available from: https://caeai.com/ansys-training/classes.

18. V. Ulmanu, G.D., V. Aluchi, Fracture Mechanics Testing Of High Density Polyethylene (Hdpe) Pipe Material With Compact Tension (Ct) Specimens. Journal of Engineering Studies and Research, 2011. 17(3): p. 98-103.

19. Benabed, T.S.a.F., Dielectric proprieties determination of high density polyethylene (HDPE) by Dielectric spectroscopy. International Journal of Materials, Mechanics and Manufacturing, 2015. 3(2): p. $121-124$. 